\title{
Sewing needle in a root canal: a case report
}

\author{
İsmail Uzun*, Buğra Güler and Taha Özyürek
}

*Correspondence: ismail.uzun@omu.edu.tr

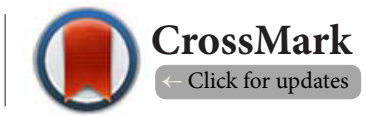

Department of Endodontics, Faculty of Dentistry, Ondokuz Mayıs University, Samsun, Turkey.

\begin{abstract}
Foreign bodies in root canals are rarely seen, and usually objects are accidently lodged and broken in root canals by the patients themselves. The occurrence of a foreign body, such as a metal screw, staple pin, sewing needle, pencil lead, bead or toothpick in the root canal system, makes the eradication of microorganisms impossible. Due to difficulties of eradicating microorganisms, foreign bodies may become sources of infection. These objects must be removed. This case report describes a rare clinical case in which a sewing needle, inserted into the root canal by the patient, was removed the orthograde approach with the aid of ultrasonic devices.
\end{abstract}

Keywords: Foreign bodies, root canal treatment, sewing needle, endodontics

\section{Introduction}

The ideal outcome of root canal treatment is the eradication of microorganisms from the root canal system, or at least their significant reduction to levels compatible with periradicular tissue healing [1]. The occurrence of a foreign body, such as a metal screw, staple pin, sewing needle, pencil lead, bead or toothpick [2] in the root canal system, makes the eradication of microorganisms impossible. Cases of foreign bodies in the root canal system are rare in literature. The presence of foreign bodies may be asymptomatic and revealed accidentally or during the radiographic examination [3], but foreign bodies often cause pain and infection.

This case report describes a rare clinical case of an immature maxillary anterior tooth with sewing needles inside root canal and its non-surgical retreatment.

\section{Case report}

A 13-year-old female patient with a history of unsuccessful endodontic treatment of a maxillary central incisor was referred to the Department of Endodontics. According to the patient's history, the crown of both maxillary central incisors had been fractured four years earlier as a result of trauma. The patient had applied to a general dentist the same day. The general dentist had performed endodontic treatment with two visits. After the second appointment the patient had not gone to a dentist. Six months before applying to our department, the patient had accidentally broken a darning needle in her left maxillary central incisor.

In the clinical examination the left maxillary central incisor was found to be grossly decayed with an open pulp chamber. Also clinical inspection revealed a metallic object in the entrance of the root canal. A periapical radiograph was taken and showed the presence of an unusual metallic radiopaque object with a round head at one end and a sharp end at the other (Figures 1 and 2). It was located close to the root apex of the left maxillary central incisor. The tooth was asymptomatic and the patient had no discomfort.

The tooth was isolated with a rubber dam and the access was modified. Attempts to bypass the metallic object failed and the decision was made to use an ultrasonic unit. The application of the ultrasonic tip directly against the exposed end of the metallic object resulted in the breakage of the metallic object. With a second application of the ultrasonic tip directly against the exposed end of the metallic object, breakage occurred again (Figure 3). After loosening and removing most of the metallic objects using the ultrasonic tip, the rest of the object was retrieval by irrigation, using $5.25 \%$ sodium hypochlorite $(\mathrm{NaOCl})$.

The working length was determined with an electronic apex locator (Root ZX mini, J. Morita Corp., Kyoto, Japan). Biomechanical preparation was achieved with the ProTaper Rotary System (Dentsply Maillefer, Ballaigues, Switzerland) up to F5 size under copious irrigation with 5.25\% NaOCI. Then root canal was dried with sterile paper points, dressed with calcium hydroxide (Calsin, İzmir, Turkey) and restored with a temporary 
filling (Cavit G, 3M ESPE, Seedfeld, Germany). Ten days later at the second appointment, the tooth was fully asymptomatic. The temporary filling was removed and the root canal was irrigated with 5.25\% NaOCI and 17\% EDTA. For the final irrigation, 5.25\% $\mathrm{NaOCI}$ was used. The canals were dried with sterile paper points and obturated by the cold lateral compaction technique with

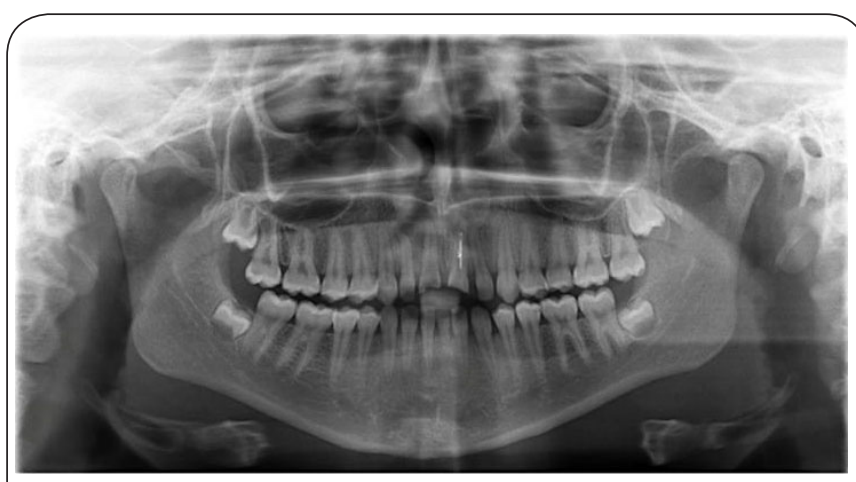

Figure 1. Panoramic radiography of the patient.

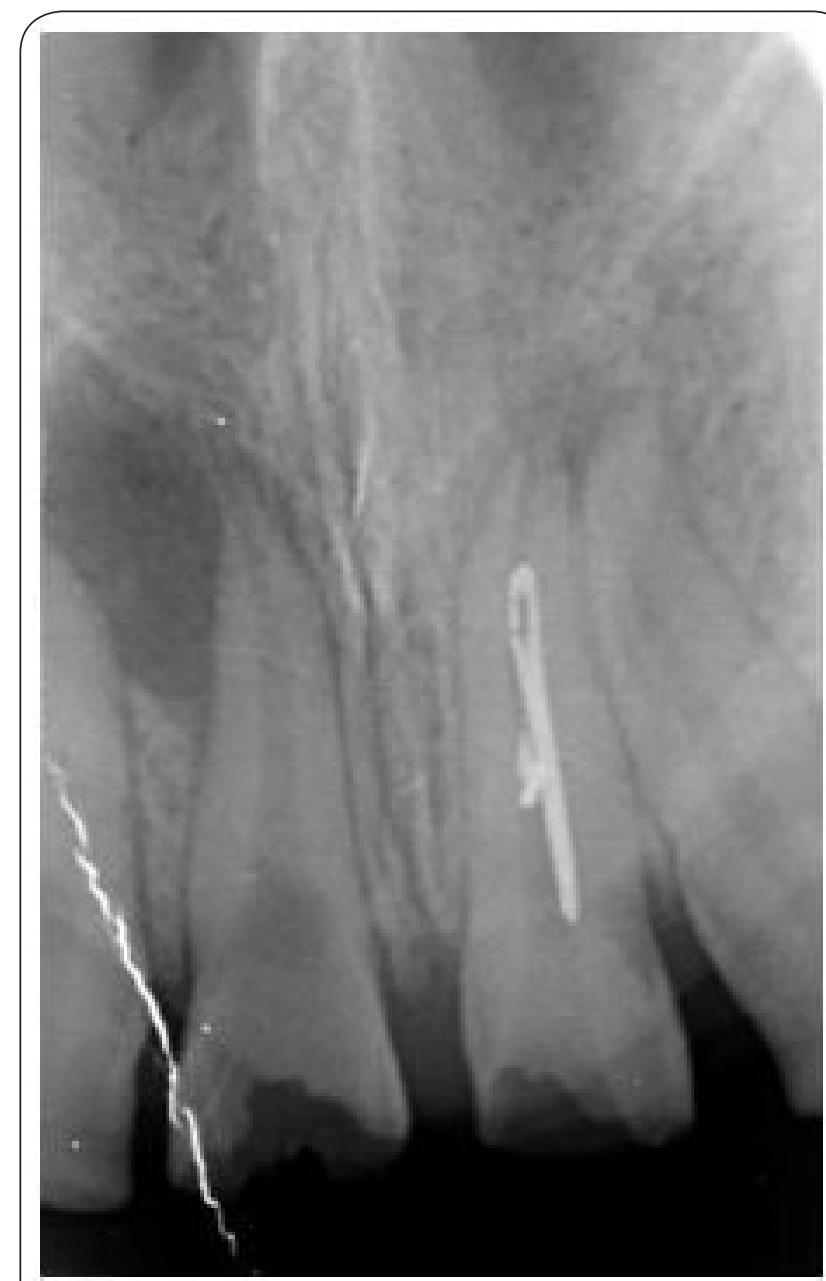

Figure 2. Periapical radiograph of left maxillary central incisor showing the foreign body.

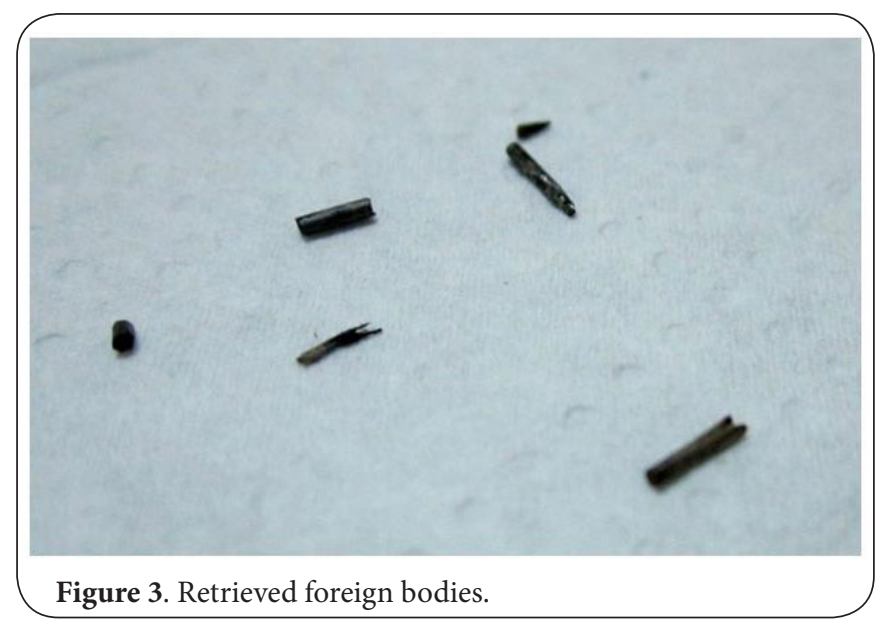

AH Plus (Dentsply, Konstanz, Germany) and gutta-percha. The tooth was restored with a light-cured composite resin (Gradia GC, Tokyo, Japan).

Three months later at the control visit, the tooth was fully asymptomatic and the patient had no discomfort. There was no pathology in the periapical area (Figure 4).

\section{Discussion}

If the period between preparation and root canal filling is extended, as in this case, some unexpected complications may appear. If the root canal is open, the patient may try to clean the obstructing food substances from the canal with various objects that may break and get lodged in the pulp space.

Foreign objects in the root canal can be a source of infection [4] and should be removed. This may sometimes be very difficult because of the shape, size and position of the foreign body. The degree of difficulty depends also on the time that has elapsed since the foreign body was inserted in to the root canal.

Technical equipment should not be considered the only factor influencing the success or failure of removal procedures; the operator's experience and skill as well as the patient's anatomical factors are also important. The removal of foreign objects is sometimes difficult and the success rate has been reported to be $55 \%$ to $79 \%$ [5].

Many methods are described for removing broken instruments or objects within root canals, such as hand instrumentation, ultrasonic devices, the Masserann Kit, the Canal Finder System or even surgical methods [6]. Most recently, the use of ultrasonic tips has been found to be the most effective method for removing separated instruments from root canals without sacrificing a great deal of sound dentin [7].

If much time has elapsed with a metallic foreign body in the root canal there is the possibility of corrosion as in this case. Corroding metallic bodies can become more fragile and, as in this case, may break when retrieval is attempted.

Foreign bodies in the root canal system should be removed for successful endodontic treatment. These objects can clearly cause infection and pain. Non-surgical endodontic treatment 


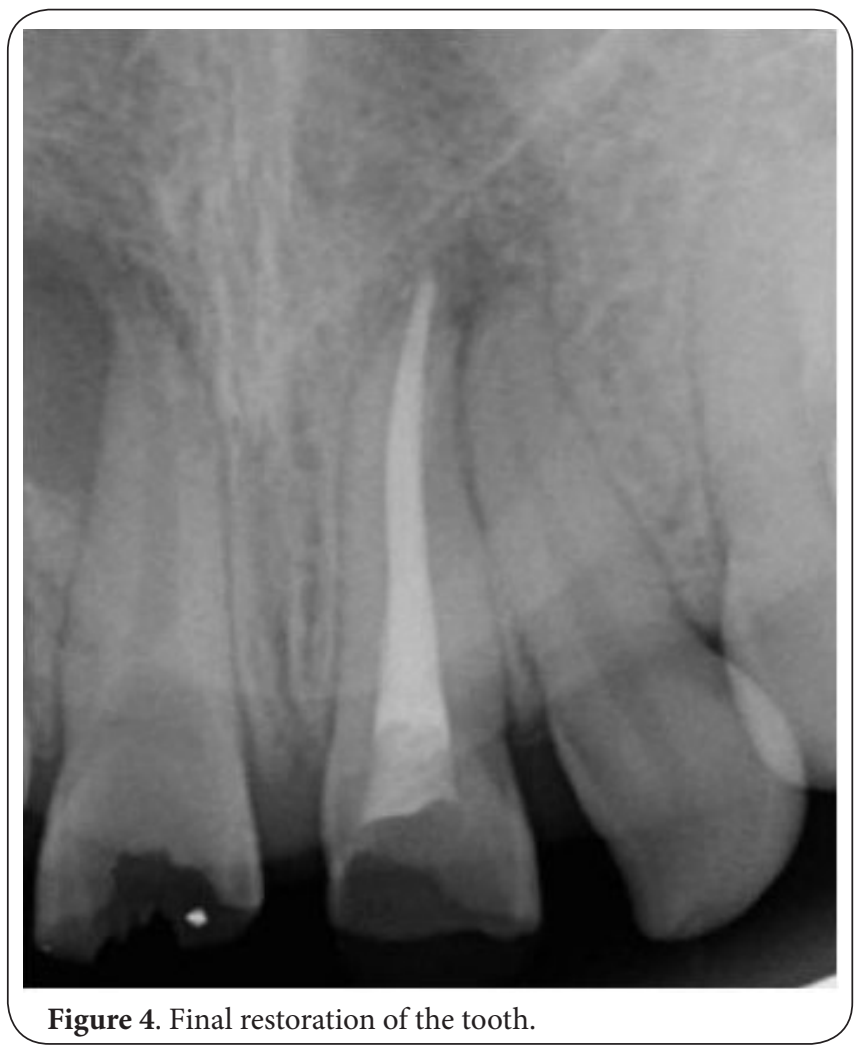

should be tried first, but in some cases endodontic surgery may be required.

\section{Conclusion}

In the literature, removal of foreign objects from root canals has been widely discussed and various techniques have been suggested. Foreign bodies in the root canal system should be removed for successful endodontic treatment. These objects can clearly cause infection and pain. With appropriate diagnostic and treatment tools, as well as good patient cooperation, management of foreign object removal from root canals can be quite straightforward. Non-surgical endodontic treatment should be tried first, but in some cases endodontic surgery may be required.

\section{Competing interests}

The authors declare that they have no competing interests.

\section{Authors' contributions}

All authors contributed equally to the manuscript.

\section{Publication history}

Received: 12 June 2014 Revised: 03 September 2014

Accepted: 07 October 2014 Published: 15 October 2014

\section{References}

1. Siqueira JF, Jr. and Rocas IN. Clinical implications and microbiology of bacterial persistence after treatment procedures. J Endod. 2008; 34:1291-1301 e3. | Article | PubMed

2. McAuliffe N, Drage NA and Hunter B. Staple diet: a foreign body in a tooth. Int J Paediatr Dent. 2005; 15:468-71. | Article | PubMed

3. Mazinis $E$, Lambrianidis $T$ and Margelos J. Detection of a residual foreign body during root canal treatment. J Endod. 2005; 31:691-3. | Article | PubMed

4. Goldstein BH, Sciubba JJ and Laskin DM. Actinomycosis of the maxilla: review of literature and report of case. J Oral Surg. 1972; 30:362-6. I PubMed

5. Nagai O, Tani N, Kayaba $\mathrm{Y}$, Kodama $\mathrm{S}$ and Osada T. Ultrasonic removal of broken instruments in root canals. Int Endod J. 1986; 19:298-304. | Article I PubMed

6. Hulsmann M. Removal of silver cones and fractured instruments using the Canal Finder System. J Endod. 1990; 16:596-600. | Article | PubMed

7. Ward JR, Parashos $P$ and Messer $\mathrm{HH}$. Evaluation of an ultrasonic technique to remove fractured rotary nickel-titanium endodontic instruments from root canals: an experimental study. J Endod. 2003; 29:756-63. | Article | PubMed

\section{Citation:}

Uzun İ, Güler B and Özyürek T. Sewing needle in a root canal: a case report. Oral Biol Dent. 2014; 2:11. http://dx.doi.org/10.7243/2053-5775-2-11 